\title{
Pathways to Gender Equality: A Configurational Analysis of Childcare Instruments and Outcomes in 21 European Countries ${ }^{1}$
}

\begin{abstract}
The ability to produce desired outcomes represents an important basis of the legitimacy of social policies. Nonetheless, policy outcomes have not systematically figured in the analysis of childcare regimes despite growing political interest in issues such as female employment, gender wage gap and men's involvement in childcare. In this article, we use fuzzy set qualitative comparative analysis to investigate the relationship between the configuration of policy instruments, attitudes toward childcare and outcomes in 21 European countries. Our results show that there is only one mix of policy instruments consistently linked with positive gender equality outcomes and this route has the quality of the universal caregiver model. It also demonstrates that both a combination of policy instruments and favourable attitudinal factors are necessary to produce desirable outcomes in the gender division of paid work and unpaid childcare.
\end{abstract}

Keywords: childcare, welfare state typology, outcomes, Fuzzy set QCA, gender division of labour

\section{Introduction}

Childcare policy is an important area of social policy intervention and one of the few areas of increased expenditure across mature welfare states (Daly and Ferragina, 2017; Ferragina et al., 2013). Despite this common trend, there is still considerable diversity in national childcare packages with different implications for gender equality (Mahon et al., 2012). The prevailing approach to mapping cross-national differences in childcare policies relies on the analysis of policy design and the institutional characteristics of particular policy instruments which are used to devise typologies of childcare regimes based on different underlying dimensions (An and Peng, 2015; Ciccia and Bleijenbergh, 2014; Javornik, 2014; Saraceno, 2011; Szelewa and Polakowski, 2008). While these typologies clearly demonstrate the existence of a variety of institutional arrangements across countries, it is less clear whether these differences translate in different patterns of desirable gender equality outcomes.

The ability to produce desirable outcomes represent an important basis of the legitimacy of social policies, and recently a growing number of authors have investigated the relationship between welfare regimes and policy outcomes (Ferragina et al., 2015; Goodin et al., 1999; Kammer et al.,

\footnotetext{
${ }^{1}$ All authors contributed equally to this work
} 
2012). Nonetheless, policy outcomes have not systematically figured in the analysis of childcare regimes despite growing political interest in issues such as female employment, gender wage gap and men's involvement in childcare. The assessment of childcare policy outcomes is complicated because the relationship between policies and outcomes is not straightforward, but rather mediated by the characteristics of the broader context as well as those of households (Kurowska, 2016). In particular, social norms and attitudes about the desirable forms of care for children may limit the use of childcare services even where they are available and affordable (Kremer, 2006). Furthermore, the definition of desired outcomes is a deeply contested issue in the field of childcare policies because of the diverse and often contrasting aims that are often attributed to such measures (e.g. increasing fertility, reducing the intergenerational transmission of disadvantage, increasing maternal employment and promoting men's engagement in childcare). From a gender perspective, the debate has moved from emphasizing the relationship between childcare measures and female employment to the inclusion of other outcomes, in particular the persistence of strong gender imbalances in the provision of childcare (Ciccia and Bleijenbergh, 2014; Kurowska, 2016; Müller et al., 2018). However, we still know little about the relationship between childcare regimes and gender equality outcomes, and the extent to which similar policies lead to different outcomes under different cultural conditions.

This article investigates the extent to which different childcare policy configurations produce transformative outcomes in the gender division of employment and care work in 21 European countries. Childcare policies comprise a mix of instruments; in this paper we focus in particular on early childhood education and care (ECEC) services and parental leave regulations. The aim of this paper is two-fold: first, we contribute to the literature on comparative childcare policy by adding the dimension of policy outcomes and its relation to policy instruments; secondly, we investigate to what extent the transformative potential of childcare policies is dependent on the dominant social attitudes and ideas about childcare. Our analytical strategy relies on the use of qualitative comparative analysis to identify necessary and/or sufficient combinations of conditions - i.e., 
configurations of childcare instruments - associated with particular outcomes. In a second step, we analyse the relationship between policy configuration and dominant social attitudes about childcare. The article is structured as followed: firstly, we review the literature on childcare regimes to clarify the relationship between childcare instruments, desirable policy outcomes and social attitudes. Then, we describe our data, methods and analysis. Thereafter, we assess countries' membership in policy configurations and investigate their relation to desired policy outcomes and attitudinal variables about the primacy of women in childcare.

\section{Dimensions of childcare policies and desirable gender equality outcomes}

In this section we review the main theoretical frameworks used in comparative analyses of childcare policies and discuss their implications in terms of defining desirable gender equality outcomes. We focus in particular on the concepts of familialization/defamilialization (Lister 1997; Saraceno, 1997) and models of division of labor (Crompton, 1999; Lewis, 1992) given their prominence in the development of typologies of childcare regimes.

Lister (1997) formulated defamilialization to bring attention to relations of dependence within the family and the influence of welfare states in patterning these relations. Here, defamilialization was used as synonymous of the individualization of social rights, i.e. the extent to which social rights were granted independently of family relations. This concept has undergone a significant shift in meaning after Esping-Andersen (1999) used it to revise his earlier analysis of welfare regimes. Since the publication of this work, defamilialization has been used increasingly less to investigate women's position vis-a-vis the whole of the welfare state and circumscribed to the analysis of childcare policies (An and Peng, 2015; Javornik, 2014; Szelewa and Polakowski, 2008). Defamilialization in this tradition becomes synonymous with policies that relieve families from caring obligations by moving (some) care to other institutions. Many successive works have shared this focus, often in view of facilitating women's employment'. A problem with this use of defamilialization is that families remain 
the main unit of analysis, and women are considered only implicitly by virtue of persisting inequalities within the family and their superior responsibility for care work. In terms of gender equality outcomes, this definition of defamilialization emphasizes the extent to which women are unburdened from caring responsibilities in order to be able to participate equally in the labour market. Nonetheless, the emphasis on paid employment neglects the need of interventions addressing persisting gender inequalities in unpaid care work such as parental rights' to time to care (Knijn and Kremer, 1997) and state influence on men's participation in caregiving (Ciccia and Verloo, 2012).

The point of departure of the second approach was the construction of policy regimes based on family forms and the gender division of labour. This research tradition was pioneered by authors such as Jane Lewis (1992) and Rosemary Crompton (1999). Lewis (1992) argued that the idea of the male breadwinner family model had cut across all modern welfare states, but that this model had been subsequently modified in different ways across countries. At the core of her analysis is the structure of women's entitlements - as wives, mothers, or workers - which is used to identify the assumptions about gender roles and the division of labour underpinning different welfare regimes. A more normative approach is proposed by Nancy Fraser (1994), who identifies the universal caregiver as a societal ideal leading to greater equality by promoting transformative gender roles. At the centre of her work is the idea that gender equality requires not only greater engagement of mothers in employment, but also that men become active care providers and share equally childcare and other types of unpaid care. Indeed, there is an increased consensus that women cannot achieve equality with men, even if in employment, as long as men do not share caregiving tasks (Pedulla and Thébaud, 2015). Several efforts have been made to operationalize the universal caregiver in terms of policy regimes or transformative policy templates (Ciccia, 2017; Ciccia and Bleijenbergh, 2014; Ciccia and Verloo, 2012; Gornick and Meyers, 2009; Rubery, 2015). Such policy models are built on a comprehensive policy mix that emphasizes the interplay of different instruments, particularly leave and childcare services. In terms of gender equality outcomes, this approach emphasizes the need of 
transformative policies both in the domains of employment and care. Drawing on these works, we define desirable gender equality outcomes as the balanced gender division of both unpaid care and paid work. This entails: 1 ) equal time spent on caring tasks by men and women; 2) equal access and quality of paid employment, including pay (Rubery, 2015)

The approach based on models of division of labour is also useful to identify different ideal types of childcare policies and their gender (in)equality underpinnings (Ciccia, 2017). The four models described in figure 1 differ with regard to two dimensions: 1) the extent to which leave policies aim to transform gender roles; 2 ) the extent to which parental care is supported by the state (figure 1).

[Figure 1 here]

The male breadwinner reinforces traditional gender roles because of the low financial retribution of periods of leave, few incentives for fathers to use leave and costly and/or scarce childcare services. These childcare regimes are generally associated to negative employment outcomes for women, who remain primarily in charge for providing childcare. The caregiver parity also promotes traditional gender roles, but the state provides long periods of well-paid maternity leaves and child allowances to compensate mothers (but not fathers) for care work, thus reinforcing ideas about the mother as the ideal caregiver. Both the male breadwinner and caregiver parity models adhere to an ideology of maternalism which exalts women's capacity as mothers and view women as primary caregivers (Orloff, 2006). Thus, men enjoy few childcare related rights in these countries, particularly in relation to leave provisions. In the Universal Breadwinner (or dual earner model), the state takes over childcare responsibility by providing affordable and widely available ECEC services. This model promotes high level of maternal employment, but parental leaves are limited and time off from work not generally rewarded. Fathers' involvement in childcare is not explicitly recognized in this model, which thus implicitly reproduces traditional gender divisions in the home and a prevalence of women in care jobs. Only the universal caregiver aims to transform gender roles inside and outside the 
labour market, while also explicitly recognizing caregiving rights and the societal value of care work (Fraser 1994). Policy packages which promote this ideal comprise leaves of moderate duration, paid at a level similar to previous wages, incentives for fathers to take substantial periods of childcare leave (e.g. daddy quotas) and good quality, affordable childcare services supporting and complementing parental childcare.

\section{Policy instruments, outcomes and social attitudes}

While there is a wide agreement in the literature that childcare policies influence both women's employment and the gender division of childcare in the home (Brandth and Kvande, 2011; Müller et al., 2018), the extent to which different national policy packages lead to transformative outcomes in the division of labour remains underexplored. Diversity in the timing, design and extent of childcare policies generally do not follow prevailing welfare regime typologies (Ciccia, 2017; Saraceno, 2011). One explanation behind this divergence is the stronger normativity of family policy (Kremer, 2006). Debates about what constitutes proper childcare have increasingly entered the political arena and national policy packages embody very different understandings of motherhood and fatherhood, which makes the explanatory routes of family policy often different from other policy areas (Mahon et al., 2012).

In Figure 2 we illustrate our theoretical framework which describes gender equality outcomes (D) as structured by the interplay between policy instruments and attitudinal factors (C). It shows that similar policy designs can produce different impacts due to: 1) the inherent interplay between policy instruments (A), and 2) their embeddedness in normative contexts which either transform or reinforce the existing gender division of paid work and unpaid childcare (B).

Policies instruments (A) contribute to shape the 'menu of options' available to individuals to make choices about work and childcare (Hobson, 2018). On the one hand, they create opportunities and provide material incentives for individuals to adopt certain behaviours (e.g. be in employment, share equally childcare); yet, on the other, they also endorse, legitimize and reproduce the 'ethos' of 
social norms and practices (Javornik, 2014). The aim of research reviewed in section two was exactly that of making explicit gender norms encoded into the design of policy instruments. Kremer (2006: 263) emphasize that such norms possess a moral dimension, "care ideals identify what is 'appropriate care'; they are the answer to the moral predicament between working and caring that many parents-most often mothers-feel they are in". In particular, care ideals embodied in social policies specify a definition of childcare, an idea about who gives it and where, and how much care should be provided. It is important to notice that childcare policies are not completely coherent and often embody multiple ideals, although some might be more dominant than others (Ciccia, 2017). The second aspect of our framework points to the fact that care ideals and gender norms contained in a particular mix of policy instruments need to resonate with prevailing social attitudes to transform the traditional division of labour (B). Clearly, there is a degree of endogeneity between social and policy norms, and indeed childcare policies often aim to, and sometimes do, seed new norms that can have destabilizing effects on conventional assumptions about the division of paid and unpaid work. Whether they are successful often depends not only on the particular policies implemented, but also on the presence of favourable public discourses, government campaigns and the support of trade unions and employers' organizations (Hobson, 2018). However, our main point here is that the transformative potential of particular policy configurations $(C)$ is shaped by how they are perceived at the societal level given prevailing attitudes about good childcare, motherhood and fatherhood. In other words, there is always a possibility that childcare ideals as described in particular policy instruments collide with wider social attitudes about 'proper' childcare. In particular, the resilience in many countries of a 'culture of social obligation' (Daly, 2002) or 'compulsory altruism' (Land and Rose, 1985) that assigns the primary responsibility for childcare to mothers might act as an obstacle to a balanced division of childcare (and limit fathers' parenting opportunities) despite the presence of favourable configurations of childcare policy instruments (Javornik, 2014; Kurowska, 2016). 
[Figure 2 here]

Stemming from the discussion above, three main assumptions inform this article. First, the ability of childcare policies to produce transformative gender equality outcomes depends on the design and interplay between different policy components and their features (configuration of policy instruments) (A). Secondly, from a normative perspective, childcare policies should be conducive to gender equality in both domains of care and employment (desired policy outcome). Thirdly, social attitudes and prevailing norms (B) about what constitutes 'good childcare' - its ideal location and related ideas about good motherhood and fatherhood - mediate the transformative potential of particular configurations of policy instruments (C) on gender equality outcomes (D) (Kremer, 2006; Kurowska, 2016). In particular, the inclusion of social attitudes in our analysis enables us to highlight the importance of both material/policy-driven and cultural factors in shaping the gender division of labour.

\section{Data and method: empirical insights and descriptive statistics}

We employ fuzzy-set qualitative comparative analysis (fsQCA) to explore the relationship between configurations of policy instruments and transformative gender outcomes in work and care. FsQCA is a set-theoretical approach introduced by Charles Ragin (1986) to detect configurational relations between condition and outcome sets. The relationships between these sets are captured in the notions of necessity and sufficiency. In contrast to other methods commonly used to develop typologies of childcare policies (e.g. cluster analysis and composite indices), QCA allows to simultaneously considers both policies and related outcomes, while also detecting the presence of alternatives routes (or functional equivalents) consistently linked to the outcomes.

To assess the validity of our findings, we report consistency and coverage parameters. Consistency indicates the goodness of fit or degree of validity of a configuration and is measured as 
the proportion of cases with the combinations of condition $\mathrm{X}$ which present also the outcome $\mathrm{Y}$. The meaning of coverage is similar to the 'variance explained' in regression analysis, and indicates how much of the outcome $Y$ is explained by the combination of conditions $X$. These two indicators tend to be negatively associated - the stricter the consistency threshold, the fewer the cases explained and vice versa. In addition to consistency and coverage, we also report the proportional reduction in inconsistency (PRI), which is a measure of the strength of the argument that a certain combination of conditions could also produce the negative outcome. We use the R package QCA to conduct the analysis (Dusa, 2019) and ggplot2 for figures (Wickham, 2016).

To identify the particular configurations of childcare policy instruments leading to transformative gender equality outcomes we transformed the raw data into set membership scores. This process of calibration entails the choice of three qualitative anchors for each outcome and condition included in the analysis: fully in (1), fully out (0), and the crossover point (0.50). In Table 1, we detail the measures and calibration used (see Appendix 1 for raw and calibrated data). There are 21 countries for which comparable data was available: Austria (AT), Belgium (BE), Bulgaria (BG), Czech Republic (CZ), Germany (DE), Denmark (DK), Estonia (EE), Spain (ES), Finland (FI), France (FR), Great Britain (GB), Hungary (HU), Ireland (IE), Iceland (IS), Lithuania (LT), Latvia (LV), the Netherlands (NL), Poland (PL), Sweden (SE), Slovenia (SI), and Slovakia (SK).

[Table 1 here]

\subsection{Outcome: gender balance in care and employment}

In this paper, we defined transformative gender equality outcomes as a balanced division of: 1) unpaid care, and 2) paid work. To measure these outcomes, we have developed separate indicators of the gender balance in unpaid care $(C)$ and paid employment $(E)$ as well as their combination (CE). While these outcomes are generally considered separately and analyses tend to give prominence to one over the other, only their combined assessment allows to assess the relation between childcare instruments and gender equality outcomes (cf. section 2). In this view, the single $\mathrm{C}$ and $\mathrm{E}$ outcomes 
give indication of the areas in which there has been more (or less) progress, but only the combined CE outcome provides a comprehensive measure of gender equality.

Gender balance in care (C) was operationalized using data from the International Social Survey Program for 2012. In particular, we have used an indicator that reports the time spent by women and their partners in providing care to other family members. ${ }^{\text {iii }}$ The index is constructed as follows:

$$
\mathrm{C}=\text { (women's care time }- \text { men's care time) / (women's care time + men's care time). }
$$

Although the index varies theoretically between -1 (men perform all the childcare) and 1 (childcare is done only by women), in all countries women dedicate more time to childcare than men with values varying between 0.14 in Sweden where women still do more care work than men, and 0.49 in Lithuania where women do almost three times more care work than men (see Figure 3). To transform raw scores into fuzzy scores, we set the minimum threshold to zero (women and men provide the same amount of childcare) and the maximum to 1 (women perform all childcare). The crossover point is at $\mathbf{0 . 3 3}$, corresponding to situations where women do twice as much care time as men. By choosing a crossover point at 0.33 , we have taken an empirical approach which recognizes the practical difficulties in achieving a gender balanced division of care. In this view, countries with scores above 0.33 have been more successful in approaching this goal even though they may still be far from a well-balanced division of childcare.

[Insert Figure 3 here]

Ten out of twenty-one countries show positive outcomes ( $\mathrm{fs}>0.50$ ). The Nordic countries (Denmark, Finland, Iceland, Sweden) have the highest scores, followed by some eastern European countries (Estonia, Latvia, Slovenia), Spain and Germany. The largest imbalances are found in postSoviet (with the exception of Estonia Latvia and Slovenia) and liberal countries.

The gender balance in employment $(\mathrm{E})$, was measured by combining information on employment

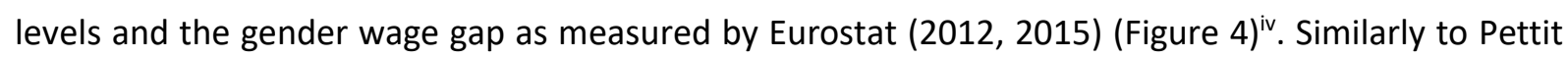


and Hook (2012), we argue that there are considerable trade-offs between the level of inclusion of women in the labour market and the quality of this inclusion. In addition, the gender wage gap reflects the presence of occupational segregation and gender differences in working hours: in countries where women are concentrated in certain sectors and occupations, including highly feminized part-time jobs, the gender wage gap tends to be higher. Our data show that the average wage gap (17 per cent) is higher than the average employment gap (8 per cent), indicating that greater equality in employment levels does not necessarily yield greater equality of wages. In order to account for this aspect, the employment index was constructed as follows:

$$
E=\min \text { (participation gap; wage gap). }
$$

The assumption underlying this measure is that a gender-balanced division of employment requires both female participation rates similar to those of men and equal pay, and that compromises between these two dimensions are not allowed. Figure 4 scatters these two dimensions. In calibrating the employment outcome, we followed a two-step logic by first calibrating each dimension-participation and wage gap-separately, and then calculating their intersection (or minimum value). Based on the chosen thresholds, ten countries scored relatively well on both participation and pay (lower-left quadrant in Figure 4). To emphasize the interplay between care and employment, we have included information on the care index in Figure 4 by means of the size of the country's bubble-the bigger the bubble, the more balanced the care index.

[Figure 4 here]

The combined outcome (CE) provides indication of how well a country performs on both dimensions:

$$
C E=\operatorname{MIN}(C, E) .
$$

Seven countries - Denmark, Finland, France, Island, Latvia, Sweden and Slovenia - show positive CE outcome. Belgium, Bulgaria and Lithuania do well do well only with regard to employment outcomes, 
while Germany, Estonia and Spain do well only on the care dimension. We proceed by detailing the calibration of the conditions included in the analysis.

\subsection{Parental leave policies}

Parental leave policies provide job-protected leave from work to parents around the time of the birth of a child. In most countries, leave can be distinguished based on the subject who is entitled: maternity (mother), paternity (father) and parental leave (both parents). By separating these different entitlements, leave legislation draws clear boundaries between the responsibilities of mothers and fathers with potentially long-lasting effects on the domestic division of childcare (Brandth and Kvande, 2009). Many countries provide financial compensation during at least some portions of these periods in the form of either wage-related or flat-rate benefits. In recent decades, new legislation in many countries has also tried to address the problem of the overrepresentation of women among leave users by introducing incentives for fathers to be more active in childcare.

We measured leave entitlements along two dimensions: the generosity of provisions (LG) and the presence of incentives for fathers (LF). LG was measured through a composite index calculated as product of the number of paid weeks by the wage replacement rate (OECD, 2016). LF was measured by the presence of incentives for fathers to take leave in the form of use-it-or-lose-it individualized entitlements such as daddy quotas and other measures that reserve portions of leave only for fathers (OECD, 2016). Both measures are presented in full-rate equivalents (FRE) as the number of weeks as if they were paid at 100 per cent of previous earnings. The use of FRE reflects the fact that leave provisions are meaningful only when the degree of wage compensation is sufficiently high for parents to be able to choose to stay home - the majority not being able to afford long periods of unpaid leave (An and Peng, 2016; Szelewa and Polakowski, 2008). Figure 5 shows that both dimensions vary dramatically across Europe. The maximum value of $L G$ is 85 weeks (Estonia) and the minimum 8.9 (Ireland). We chose an intermediate threshold of 40 FRE weeks since periods of around one year are generally considered to have positive effects on maternal employment and child 
development (Evertsson \& Duvander, 2010). The minimum threshold is set at 12 weeks which is close to the minimum entitlement required by the EU maternity leave directive.

[Figure 5 here]

LF ranges from zero in the Czech Republic, Ireland and Slovakia to 10.9 weeks in Sweden. The crossover point corresponds to at least three fully-paid weeks. Figure 5 indicates that there are twelve countries with positive outcomes (all the post-Soviet countries, Germany, Austria and Finland). Eight countries - Austria, Belgium, Germany, Finland, France, Latvia, Iceland and Sweden meet the criteria for fathers' incentives. Only four countries - Austria, Germany, Finland and Latvia have membership scores above 0.50 .

\subsection{Early Childhood Education and Care (ECEC)}

ECEC include care-related and educational services for children below school age. In the context of increased emphasis on labour market participation, they have become an essential tool to raise maternal employment levels. However, it is more difficult to assess their influence on the gender division of childcare within the home (Ciccia and Bleijenbergh, 2014; Crompton, 2006).

There are many facets involved in the organization of ECEC. Data on the institutional characteristics of ECEC systems is scarce because of large cross-national and sub-national variations, the intersection of responsibilities between education and social care systems and the presence of different public and private mixes in many countries. Given this situation, previous studies have typically relied on measures of policy outcomes (e.g. enrolment rates or public expenditure). However, this approach is problematic because usage rates are partly endogenous and dependent on the length of available leave, while the value of public expenditure is also dependent on the quality of services and the number of recipients.

Given the limitations of previous measures, we adopted a subjective approach to measure important features of ECEC provisions, which relies on data from the European Quality of Life Survey, 
2012 (Q55a, Q55b). We focused, in particular, the percentage of parents that reported finding it very difficult to use services due to either their cost/affordability (CC) or availability (CA) ${ }^{v}$. The crossover points were set at 0.20 , i.e. we consider that childcare services are affordable or available if less than 20 per cent of respondents reported these issues to be very difficult. In figure 6 , we combine this data with information on the participation rate of children up to 4 years old in childcare to contrast patterns of coverage and subjective assessments.

\section{[Figure 6 here]}

Figure 6 shows that countries in which ECEC availability and affordability are not perceived as problematic have high participation rates (lower-left quadrant). However, in some of the countries with the lowest participation (Poland, Slovakia, Spain), availability and affordability are also not perceived to be a major problem. This confirms the complicated relationship between structural constraints and cultural norms in influencing the usage of childcare services (Hobson,2018; Kremer, 2007). The share of people reporting availability as very difficult varies between 5.4 in Demark and 40.8 in France. In France, children's participation in childcare is among the highest but regional shortage of services has become a salient issue (Lewis et al., 2008). In Estonia, parents also report finding it very difficult to secure a childcare place, despite this being an established social right as in the Scandinavian countries. The share of parents that find affordability very difficult varies between 1.5 per cent in Sweden and 43.3 per cent in the UK.

\section{Results}

Following common QCA standards, we proceed from necessity to sufficiency analysis (Schneider and Wagemann, 2012). The necessity analysis reveals that only affordability of ECEC services (CC) is a necessary condition in configurations leading to a balanced division of work and childcare (CE) (consistency $\geq 0.90$ ) (table 2 ). And the necessity criteria of CC holds only in case of combined 
outcome (CE). In what follows we focus on the analysis of sufficient conditions by including all four conditions to investigate configurations of policy instruments leading to transformative gender outcomes. Table 3 presents the truth tables of the countries' membership in childcare configurations and their consistencies with positive C, E and CE outcomes. The first column indicates the number identifying each configuration (assigned automatically by the software). The next four columns indicate the presence (1) or absence (0) of each policy instruments: LG -leave generosity; LF fathers' incentives, CC - childcare affordability; and CA - availability. For instance, configuration 8, which explains Iceland and Sweden, is characterized by the absence of generous leaves, the presence of fathers' incentives, affordability and availability of childcare (0111). The final column shows the membership in Fraser's typology based on the conceptualization in Section 2 and the operationalisation in Section 4.

The twenty-one countries in this analysis are represented by ten configurations (or combinations of policy instruments). For each, we report the consistency and PRI coefficients. Parameters of fit are as expected lowest for the stricter outcome CE.

[Table 2 here]

Table 3 shows great diversity in childcare policy instruments. There are four configurations $(8,7$, 15, and 16) where fathers' incentives (LF) combine with affordable childcare and different parental leave designs and childcare availability. These configurations belong to the universal caregiver model because they promote to varying degree the transformation of traditional gender roles (Fraser, 1994). These routes are generally linked to positive $C$ and E outcomes, but not necessarily the combined CE outcome. Denmark (configuration 4) belongs to the universal breadwinner model given the primacy of services over leave provisions. This model leads also to positive C, E and CE outcomes. Several Central and Eastern European countries (configurations 9, 10,11) follow instead a caregiver 
parity model characterized by generous leaves but limited childcare service provisions and incentives for fathers. This configuration $(3,11)$ does not generally lead to positive gender equality outcomes except in Slovenia and Latvia. Ireland, Netherlands, Spain and the United Kingdom characterize instead as limited universal breadwinner model because of scarce leave provisions and ECEC services which are either unavailable (Spain) or costly (Ireland, the Netherlands, United Kingdom). This model does not lead to transformative C, E, and CE outcomes.

Table 3 also indicates that non-membership in leave generosity $(<0.50$, or 40 fully paid weeks) is a INUS conditions in sufficient configurations $(7,8)$ leading to all three positive outcomes because: 1)some countries (Finland, Latvia, Slovenia) with generous leaves have also positive C, E, and CE outcomes; and 2) several countries with moderate leaves show negative outcomes. INUS or enabling conditions are casually relevant only in some cases and only in combinations with other conditions, in this case (fathers' incentive and affordable childcare) (Schneider and Wagemann, 2012). Fathers' incentives is also present in all high-consistency configurations, but it's also not a necessary condition since it is also singularly present in configurations leading to negative outcomes.

We minimize the truth table to eliminate the potential redundancy of configurations. We adopt the conservative/complex solution which does not take into account any logical reminders (i.e. empty truth table rows). We set the consistency threshold at 0.75 . As Table 4 shows the consistency of the two policy configurations leading to positive $\mathrm{C}$ and $\mathrm{E}$ outcomes are above 0.80 with coverage close to 0.50 , explaining approximately half of the positive outcome cases. However, as soon as we consider the combined outcome for care and employment (CE) both consistency and coverage levels drop considerably. There is only one route leading to positive CE outcome. This route is followed by Iceland and Sweden and comes closer to implementing a universal caregiver model (Ciccia, 2017). Childcare availability, in combination with the presence of limited leaves, fathers' incentives and affordable childcare, is particularly important to produce positive CE outcomes. The truth table analysis also reveals that while countries' rankings in terms of consistencies changes slightly across outcomes (Table 3), those that meet the consistency criteria are the same across all three outcomes 
(Iceland, Sweden, Belgium and France). The same holds for the configurations that are the least sufficient for the three outcomes. In other words, our analysis indicates that care and employment are complementary rather than opposing outcomes.

[Table 3 here]

We observe that while the membership score of Finland and Germany in the recommended policy mix are quite close to 0.50 , these countries' policy configurations are insufficiently linked with positive outcomes. Finland differs from the optimal configuration because of the presence of generous parental leaves. The main reason for its low sufficiency is the presence in the same configuration of Austria and Lithuania with low scores in combined outcome dimension CE. Since these countries belong to different welfare regimes, we may speculate that in the Nordic context, generous leave does not produce as much harm as in other regional contexts. Nonetheless, data shows that the gender wage gap is higher in Finland than in other Nordic countries and as a result, the Finnish membership score (0.56) in the combined CE outcome is barely above the crossover point (see Appendix 1). Denmark presents positive outcomes on all three dimension despite the absence of incentives for fathers to use leave. This country shows the largest availability of childcare services in the region, but parental leave was introduced only in 1984, and a daddy quota was created in 1998 but soon eliminated in 2002 .

Returning to our conceptual model in Figure 2, we expect that the transformative potential of childcare policies is dependent on the relationship between the package or configuration of policy instruments and dominant social attitudes and ideas about childcare. In Figure 7, we explored this relationship by using aggregate data on parents' attitudes about childcare arrangements (share of people agreeing that leaves should be used entirely by the mother (OECD 2014) ${ }^{\mathrm{vi}}$. The threshold was set at 0.40 , meaning that for a country to be in the set of favourable attitudes at least 60 per cent of respondents in that country disagreed that leaves should be used only by mothers. Additionally, we 
calculated countries' membership in the universal caregiver model using the maximum score among configurations 8, 7, 15 or 16 (see results in Appendix 2).

[Figure 7 here]

Figure 7 shows that six countries (Denmark, Finland, France, Iceland, Slovenia and Sweden) with positive scores on attitudes with regard to leave sharing also show positive CE outcomes. In particular, the inclusion of attitudinal factors explains the positive outcomes in Denmark and Slovenia despite of the lack of father's incentives which characterizes the universal caregiver model. In Finland, the presence of long leaves is counterbalanced by positive attitudes towards father's sharing of leave entitlements which leads to positive CE outcomes. Overall, this analysis shows that a combination of policy instruments (universal caregiver configuration) and favourable attitudinal factors are necessary to produce a gender balance in the division of care and employment. However, the combination of policy instruments and attitudes does not explain two types of outcomes. First, Belgium and Germany present negative CE outcomes despite the presence of favourable attitudinal factors and policy configurations. Secondly, Latvia presents positive outcomes despite presenting unfavourable attitudinal factors and policy mix. The presence of positive outcomes in Latvia is hard to understand since childcare policies are centred on generous leaves with no incentives for fathers or affordable or available services. Technically, the low consistency of this route is related to the negative outcomes of other countries (Bulgaria and Poland) belonging to the same policy configuration.

\section{Discussion and conclusions}

The aim of this article was to investigate the relation between the configuration of childcare policy instruments, attitudinal factors and gender balance in care and employment in 21 European countries. Our findings show that positive outcomes in the division of paid employment and unpaid 
childcare reinforce each other as there are only few cases that perform well only on one of these dimensions. We also found that, contrary to our initial expectations, only one mix of policy instruments leads to transformative gender equality outcomes and this configuration has the quality of the universal caregiver model. This comprises moderate parental leaves (less than 40 fully paid weeks), the presence of fathers' incentives (more than 3 fully paid weeks) and a high perceived affordability and availability of childcare places. Our sufficiency analysis indicates that there are no functionally equivalent routes. However, Denmark following a universal breadwinner model - placing primacy on day care services over parental time rights - also produces positive outcomes, although to a lesser extent. Moreover, there are other policy configurations - for instance those characterized by generous leave, strong incentives for fathers and well-perceived childcare services - which can be interpreted as implementing a universal caregiver ideal that lead to mixed results across countries (Finland, Austria, and Lithuania). The inclusion of attitudinal variables in the analysis suggests that the same package of policy instruments works differently across contexts, and that the presence of positive attitudes towards parental sharing of childcare responsibilities can partly compensate the deficiencies of certain policy mixes. Therefore, transformative gender outcomes in childcare are not built only through policies, but are also dependent on the wider cultural context. 


\section{References}

An, M.Y., Peng, I., 2016. Diverging Paths? A Comparative Look at Childcare Policies in Japan, South Korea and Taiwan. Soc. Policy Adm. 50 (5): 540-558.

Brandth, B., Kvande, E., 2009. Gendered or Gender-Neutral Care Politics for Fathers? Ann. Am. Acad. Pol. Soc. Sci. 624, 177-189.

Ciccia, R., 2017. A two-step approach for the analysis of hybrids in comparative social policy analysis: a nuanced typology of childcare between policies and regimes. Qual. Quant. 51, 2761-2780.

Ciccia, R., Bleijenbergh, I., 2014. After the Male Breadwinner Model? Childcare Services and the Division of Labor in European Countries. Soc. Polit. Int. Stud. Gend. State Soc. 21, 50-79.

Ciccia, R., Verloo, M., 2012. Parental leave regulations and the persistence of the male breadwinner model: Using fuzzy-set ideal type analysis to assess gender equality in an enlarged Europe. J. Eur. Soc. Policy 22, 507-528.

Crompton, R., 2006. Employment and the family: the reconfiguration of work and family life in contemporary societies. Cambridge University Press, Cambridge.

Crompton, R. (Ed.), 1999. Restructuring Gender Relations and Employment: the Decline of the Male Breadwinner. Oxford University Press, Oxford.

Daly, M. 2002. Care as a Good for Social Policy. J. Soc. Policy 31(2): 251-70.

Daly, M., Ferragina, E., 2017. Family policy in high-income countries: Five decades of development. J. Eur. Soc. Policy 0958928717735060.

Dusa, A. 2019. QCA with R. A Comprehensive Resource. Springer International Publishing.

Esping-Andersen, G. 1990. The three worlds of welfare capitalism. Cambridge: Princeton University Press.

Evertsson, M.; Duvander, A.Z. 2011. Parental Leave: Possibility or Trap? Does Family Leave Length Effect Swedish Women's Labour Market Opportunities?, European Sociological Review 7(4): 435-450.

Ferragina, E., Seeleib-Kaiser, M., Spreckelsen, T., 2015. The Four Worlds of 'Welfare Reality' - Social Risks and Outcomes in Europe. Soc. Policy Soc. 14, 287-307.

Ferragina, E., Seeleib-Kaiser, M., Tomlinson, M., 2013. Unemployment Protection and Family Policy at the Turn of the 21st Century: A Dynamic Approach to Welfare Regime Theory. Soc. Policy Adm. 47, 783-805.

Goodin, R.E., Headey, B., Muffels, R., Dirven, H.-J., 1999. The real worlds of welfare capitalism. Cambridge University Press, Cambridge.

Gornick, J. C; Meyers (Eds). 2009. Gender Equality: Transforming Family Divisions of Labor. New York: Verso.

Hobson, B., 2018, Gendered dimensions and capabilities: Opportunities, dilemmas and challenges', Critical Sociology, 44(6), 883-898. 
Javornik, J. 2014. Measuring state de-familialism: Contesting post-socialist exceptionalism. Journal of European Social Policy, 24(3): 240-257.

Kammer, A., Niehues, J., Peichl, A., 2012. Welfare regimes and welfare state outcomes in Europe. J. Eur. Soc. Policy 22, 455-471.

Kremer, M., 2007. How welfare states care: culture, gender and citizenship in Europe. Amsterdam University Press, Amsterdam.

Knijn, T.; Kremer, M. 1997. Gender and the caring dimension of welfare states: toward inclusive citizenship. Social Politics: International Studies in Gender, State \& Society, 4(3): 328-361.

Kremer, M., 2006. The Politics of Ideals of Care: Danish and Flemish Child Care Policy Compared. Soc. Polit. Int. Stud. Gend. State Soc. 13, 261-285.

Kurowska, A. 2016. (De)familialization and (De)genderization - Competing or Complementary Perspectives in Comparative Policy Analysis? Social Policy \& Administration, 52(1): 29-49.

Land H, H. Rose, 1985, 'Compulsory altruism for some or an altruistic society for all?' in P. Bean, J. Ferris and D. Whynes (eds), In Defence of Welfare, Tavistock, London.

Lewis, J. 1992. Gender and the development of welfare regimes. Journal of European Social Policy, 2(3): 159-73.

Lewis, J., Knijn, T., Martin, C., Ostner, I., 2008. Patterns of Development in Work/Family Reconciliation Policies for Parents in France, Germany, the Netherlands, and the UK in the 2000s. Soc. Polit. Int. Stud. Gend. State Soc. 15, 261-286.

Mahon, R., Anttonen, A., Bergqvist, C., Brennan, D., Hobson, B., 2012. Convergent care regimes? Childcare arrangements in Australia, Canada, Finland and Sweden. J. Eur. Soc. Policy 22, 419431.

Misra, J., Budig, M. and Böckmann, I.,2010, 'Work-Family Policies and the Effects of Children on Women's Employment and Earnings', Luxemburg Income Study Working Paper Series 543, Luxembourg: LIS.

Müller, K.-U., Neumann, M., Wrohlich, K., 2018. The family working-time model: Towards more gender equality in work and care. J. Eur. Soc. Policy 28, 471-486.

Orloff, A.S., 2006. From Maternalism to 'Employment for All': State Policies to Promote Women's employment across the Affluent Democracies, in: Levy, J. (Ed.), The State after Statism. Harvard University Press: Cambridge, MA, 230-68.

Pedulla, D.S., Thébaud, S., 2015. Can We Finish the Revolution? Gender, Work-Family Ideals, and Institutional Constraint. Am. Sociol. Rev. 80, 116-139.

Pettit, B; Hook, J. L. 2012. Gendered Tradeoffs: Family, Social Policy, and Economic Inequality in Twenty-One Countries, Russell Sage Foundation: New York.

Ragin. C. 2008. Redesigning Social Inquiry. Fuzzy Sets and Beyond. University of Chicago Press.

Rubery, J., 2015. Regulating for Gender Equality: A Policy Framework to Support the Universal Caregiver Vision. Soc. Polit. Int. Stud. Gend. State Soc. 22, 513-538.

Saraceno C. 1997. Family change, family policies and the restructuring of welfare. Family, Market and Community, Social Policy Studies, no. 21, OECD, Paris, 81-100. 
Saraceno, C. 2011. Childcare needs and childcare policies: A multidimensional issue. Current Sociology, 59(1): 78.

Schneider, C. Q; Wageman, C. 2012. Set-Theoretic Methods for the Social Sciences. A Guide to Qualitative Comparative Analysis. Cambridge.

Szelewa, D., Polakowski, M.P., 2008. Who cares? Changing patterns of childcare in Central and Eastern Europe. J. Eur. Soc. Policy 18, 115-131.

Wickham, H. 2016. ggplot2: Elegant Graphics for Data Analysis. Springer-Verlag New York. 
Table 1: Dimensions, sets, operationalization and calibration thresholds

\begin{tabular}{|c|c|c|c|c|c|c|c|c|c|c|}
\hline \multirow{2}{*}{\multicolumn{2}{|c|}{ DIMENSIONS }} & \multirow[b]{2}{*}{ Labels } & \multirow[b]{2}{*}{ Sets } & \multirow[b]{2}{*}{ Operationalization } & \multirow[b]{2}{*}{ Mean } & \multirow[b]{2}{*}{ Min } & \multirow[b]{2}{*}{ Max } & \multirow{2}{*}{\multicolumn{2}{|c|}{$\begin{array}{l}\text { Calibration } \\
\text { (fully in; cross- } \\
\text { over; fully out) }\end{array}$}} & \multirow[b]{2}{*}{ Source } \\
\hline & & & & & & & & & & \\
\hline \multirow{5}{*}{ 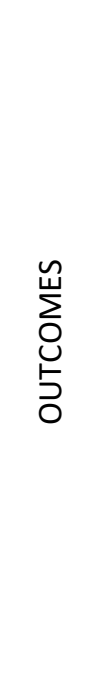 } & $\underset{⿱ 亠 凶}{\overleftarrow{c}}$ & $\mathrm{C}$ & $\begin{array}{l}\text { Gender balance } \\
\text { in care }\end{array}$ & $\begin{array}{l}\text { Care index: (Female care-male } \\
\text { care)/(female care+male care) }\end{array}$ & 0.32 & 0.14 & 0.49 & 0.1 & $0.4 ; 0.33 ; 0.2$ & ISSP 2012 \\
\hline & \multirow{3}{*}{ 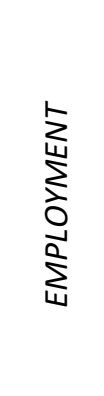 } & EP & $\begin{array}{l}\text { Employment } \\
\text { participaton }\end{array}$ & $\begin{array}{l}\text { Male employment - female employment } \\
\text { (Total employment; resident } \\
\text { population concept - LFS) }\end{array}$ & 8.89 & 2.1 & 16.6 & 4 & $14 ; 10 ; 4$ & Eurostat 2015 \\
\hline & & EW & Wage gap & $\begin{array}{l}\text { Eurostat; Gender pay gap in unadjusted } \\
\text { form in } \% \text { - NACE Rev. } 2 \text { (structure of } \\
\text { earnings survey methodology) }\end{array}$ & 17 & 2.5 & 30 & 6 & $25 ; 20 ; 10$ & Eurostat 2012 \\
\hline & & $\mathrm{E}$ & $\begin{array}{l}\text { Gender balance } \\
\text { in employment }\end{array}$ & Employment index: $E=\min (E P, E W)$ & & & & & & \\
\hline & 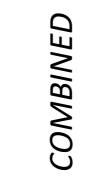 & CE & $\begin{array}{l}\text { Good policy } \\
\text { outcome }\end{array}$ & Combined index: $\mathrm{CE}=\min (\mathbf{C}, \mathbf{E})$ & & & & & & \\
\hline \multirow{4}{*}{$\begin{array}{l}\text { n } \\
\text { OO } \\
\text { 产 } \\
\sum \\
\text { O }\end{array}$} & \multirow{2}{*}{ 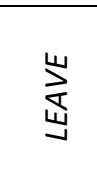 } & LG & $\begin{array}{l}\text { Generosity of } \\
\text { leave }\end{array}$ & $\begin{array}{c}\text { Maternity + parental leave in full-rate } \\
\text { equivalences (FRE) }\end{array}$ & 39.6 & 8.9 & 85 & 22 & $12 ; 40 ; 70$ & OECD 2016 \\
\hline & & LF & $\begin{array}{l}\text { Fathers' } \\
\text { incentives }\end{array}$ & $\begin{array}{l}\text { Leave reserved for fathers in full-rate } \\
\text { equivalences (FRE) }\end{array}$ & 3.2 & 0 & 10.9 & 3 & $1 ; 3 ; 7$ & OECD 2016 \\
\hline & \multirow{2}{*}{ 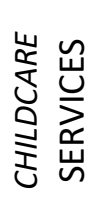 } & $\mathrm{CC}$ & $\begin{array}{l}\text { Affordability of } \\
\text { childcare }\end{array}$ & $\begin{array}{l}\% \text { of individuals that find it very difficult } \\
\text { to use childcare because of cost }\end{array}$ & 17.78 & 1,5 & 43.3 & 10.7 & $0 ; 20 ; 50$ & EQLS 2012 \\
\hline & & CA & $\begin{array}{l}\text { Availability of } \\
\text { childcare }\end{array}$ & $\begin{array}{l}\% \text { of individuals that find it very difficult } \\
\text { to use childcare because of availability }\end{array}$ & 19.15 & 5.4 & 40.8 & 9.42 & $0 ; 20 ; 50$ & EQLS 2012 \\
\hline
\end{tabular}

Note: The mean, minimum, maximum and standard deviation of $E$ and $C E$ are calculated using calibrated values based on the minimum scores of (EP, EW) and (C, E) respectively. 
Table 2: Analysis of necessary conditions for care (C), employment (E) and combined outcome (CE)*

\begin{tabular}{|c|c|c|c|c|c|c|}
\hline & \multicolumn{2}{|l|}{ CARE (C) } & \multicolumn{2}{|l|}{ EMPLOYMENT (E) } & \multicolumn{2}{|c|}{ COMBINED OUTCOME (CE) } \\
\hline & Consistency & Coverage & Consistency & Coverage & Consistency & Coverage \\
\hline \multicolumn{7}{|l|}{$\begin{array}{l}\text { The presence of } \\
\text { conditions }\end{array}$} \\
\hline Generosity of leave & 0.48 & 0.43 & 0.58 & 0.5 & 0.54 & 0.31 \\
\hline Fathers' incentives & 0.6 & 0.65 & 0.6 & 0.64 & 0.65 & 0.47 \\
\hline Affordability of childcare & 0.87 & 0.64 & 0.81 & 0.57 & 0.9 & 0.43 \\
\hline Availability of childcare & 0.71 & 0.56 & 0.71 & 0.54 & 0.8 & 0.41 \\
\hline \multicolumn{7}{|l|}{$\begin{array}{l}\text { The absence of } \\
\text { conditions }\end{array}$} \\
\hline Generosity of leave & 0.68 & 0.58 & 0.68 & 0.56 & 0.81 & 0.45 \\
\hline Fathers' incentives & 0.55 & 0.39 & 0.58 & 0.41 & 0.58 & 0.27 \\
\hline Affordability of childcare & 0.42 & 0.45 & 0.51 & 0.52 & 0.51 & 0.36 \\
\hline Availability of childcare & 0.55 & 0.54 & 0.63 & 0.6 & 0.61 & 0.39 \\
\hline
\end{tabular}

*consistency threshold $\geq .90$. 
Author accepted manuscript, accepted the $10^{\text {th }}$ of Oct 2019

Table 3: Truth table of sufficient conditions for care (C), employment (E) and combined outcome (CE)

\begin{tabular}{|c|c|c|c|c|c|c|c|c|c|c|c|c|c|c|c|c|c|}
\hline \multirow[b]{2}{*}{$\mathrm{N}$} & \multicolumn{4}{|c|}{ INSTRUMENTS SETS } & \multicolumn{4}{|c|}{ CARE (C) } & \multicolumn{4}{|c|}{ EMPLOYMENT (E) } & \multicolumn{4}{|c|}{ COMBINED OUTCOME (CE) } & \multirow{2}{*}{$\begin{array}{c}\text { Model of } \\
\text { division of } \\
\text { labour }\end{array}$} \\
\hline & $L G$ & $L F$ & $C C$ & $C A$ & Cases & Cons. & PRI & Rank & Case & $\begin{array}{c}\text { Con } \\
s .\end{array}$ & $P R I$ & Rank & Case & Cons. & $P R I$ & Rank & \\
\hline 8 & 0 & 1 & 1 & 1 & IS,SE & 0.86 & 0.60 & 1 & IS,SE & 0.78 & 0.46 & 2 & IS,SE & 0.75 & 0.37 & 1 & Universal caregiver \\
\hline 7 & 0 & 1 & 1 & 0 & $B E, F R$ & 0.82 & 0.48 & 2 & $B E, F R$ & 0.87 & 0.79 & 1 & $B E, F R$ & 0.70 & 0.11 & 2 & Universal caregiver \\
\hline 4 & 0 & 0 & 1 & 1 & DK & 0.72 & 0.21 & 4 & DK & 0.72 & 0.43 & 3 & DK & 0.62 & 0.22 & 3 & Univ. breadwinner \\
\hline 3 & 0 & 0 & 1 & 0 & ES & 0.70 & 0.39 & 5 & ES & 0.60 & 0.41 & 6 & ES & 0.55 & 0.00 & 4 & Univ. breadwinner \\
\hline 15 & 1 & 1 & 1 & 0 & DE & 0.72 & 0.32 & 3 & DE & 0.72 & 0.50 & 4 & $\mathrm{DE}$ & 0.52 & 0.02 & 5 & Universal caregiver \\
\hline 16 & 1 & 1 & 1 & 1 & AT, FI,LT & 0.67 & 0.07 & 6 & AT, FI,LT & 0.67 & 0.36 & 5 & AT, FI,LT & 0.48 & 0.09 & 6 & Universal caregiver \\
\hline 11 & 0 & 0 & 0 & 1 & IE,NL,UK & 0.55 & 0.04 & 8 & IE,NL,UK & 0.50 & 0.23 & 8 & IE,NL,UK & 0.41 & 0.00 & 7 & Univ. breadwinner \\
\hline 9 & 1 & 0 & 0 & 0 & $\mathrm{BG}, \mathrm{LV}, \mathrm{PL}, \mathbf{S I}$ & 0.59 & 0.39 & 7 & BG,LV,PL,SI & 0.50 & 0.25 & 7 & $\mathrm{BG}, \mathrm{LV}, \mathrm{PL}, \mathbf{S I}$ & 0.39 & 0.16 & 8 & Caregiver parity \\
\hline 10 & 1 & 0 & 0 & 1 & $\mathrm{HU}$ & 0.50 & 0.24 & 10 & $\mathrm{HU}$ & 0.48 & 0.14 & 9 & $\mathrm{HU}$ & 0.36 & 0.04 & 9 & Caregiver parity \\
\hline 2 & 1 & 0 & 1 & 0 & CZ,EE,SK & 0.53 & 0.21 & 9 & $\mathrm{CZ}, \mathrm{EE}, \mathrm{SK}$ & 0.46 & 0.13 & 10 & $\mathrm{CZ}, \mathrm{EE}, \mathrm{SK}$ & 0.35 & 0.08 & 10 & Caregiver parity \\
\hline
\end{tabular}

Notes: Countries in bold are those with positive outcomes in a particular dimension (C,E, CE), i.e. membership scores $>0.5$; consistency scores $\geq 0.75$ threshold are also in bold 
Table 4: Sufficient routes to outcomes

\begin{tabular}{|c|c|c|c|}
\hline OUTCOME(S) & $\begin{array}{c}\text { CARE } \\
\text { C }\end{array}$ & $\begin{array}{c}\text { EMPLOYMENT } \\
\text { E }\end{array}$ & $\begin{array}{c}\text { COMBINED } \\
\text { CE }\end{array}$ \\
\hline Generosity of leave & . & . & . \\
\hline Fathers' incentives & $\bullet$ & $\bullet$ & $\bullet$ \\
\hline Affordability of childcare & $\bullet$ & $\bullet$ & $\bullet$ \\
\hline Availability of childcare & & & $\bullet$ \\
\hline Consistency & 0.81 & 0.83 & 0.75 \\
\hline PRI & 0.69 & 0.61 & 0.37 \\
\hline Raw coverage & 0.46 & 0.48 & 0.53 \\
\hline \multirow[t]{4}{*}{ Cases } & $\mathrm{BE}$ & $\mathrm{BE}$ & \\
\hline & FR & FR & \\
\hline & IS & IS & IS \\
\hline & SE & SE & SE \\
\hline
\end{tabular}

Notes: •- condition present; - condition absent 
Appendix 1: Raw and calibrated data, main analysis

\begin{tabular}{|c|c|c|c|c|c|c|c|c|c|c|c|c|c|c|c|c|}
\hline Country & $\begin{array}{l}\text { Care } \\
\text { index }\end{array}$ & $C$ & $\begin{array}{l}\text { Employment } \\
\text { gap }\end{array}$ & EP & $\begin{array}{l}\text { Wage } \\
\text { gap }\end{array}$ & EW & $\begin{array}{l}\text { Employment } \\
\text { index }\end{array}$ & $\begin{array}{c}\text { CE } \\
\text { outcome }\end{array}$ & $\begin{array}{l}\text { Generosity } \\
\text { of leave }\end{array}$ & LG & $\begin{array}{l}\text { Fathers' } \\
\text { incentives }\end{array}$ & $\mathrm{LF}$ & $\begin{array}{c}\text { ECEC } \\
\text { Affordability }\end{array}$ & CC & $\begin{array}{c}\text { ECEC } \\
\text { Availability }\end{array}$ & CA \\
\hline AT & 0.42 & 0.02 & 8.2 & 0.71 & 23.4 & 0.12 & 0.12 & 0.02 & 51.2 & 0.75 & 6.9 & 0.95 & 10.9 & 0.8 & 10.7 & 0.8 \\
\hline $\mathrm{BE}$ & 0.34 & 0.40 & 8.3 & 0.7 & 10 & 0.95 & 0.7 & 0.40 & 13.1 & 0.05 & 5 & 0.82 & 10.4 & 0.81 & 24.4 & 0.39 \\
\hline BG & 0.42 & 0.02 & 6.6 & 0.85 & 14.7 & 0.83 & 0.83 & 0.02 & 65.5 & 0.93 & 1.7 & 0.12 & 26.3 & 0.35 & 27.5 & 0.32 \\
\hline$C Z$ & 0.38 & 0.11 & 16.6 & 0.01 & 22.2 & 0.21 & 0.01 & 0.01 & 53.1 & 0.79 & 0 & 0.01 & 17.2 & 0.6 & 22.0 & 0.45 \\
\hline $\mathrm{DE}$ & 0.31 & 0.61 & 8.7 & 0.66 & 22.4 & 0.19 & 0.19 & 0.19 & 42.6 & 0.56 & 5.7 & 0.88 & 11.6 & 0.78 & 21.4 & 0.47 \\
\hline DK & 0.22 & 0.92 & 7.5 & 0.78 & 16.8 & 0.72 & 0.72 & 0.72 & 26.8 & 0.2 & 1.1 & 0.05 & 6.3 & 0.89 & 5.4 & 0.9 \\
\hline $\mathrm{EE}$ & 0.31 & 0.60 & 7.8 & 0.75 & 30 & 0 & 0 & 0.00 & 85 & 0.99 & 2 & 0.18 & 17.6 & 0.59 & 31.6 & 0.24 \\
\hline ES & 0.27 & 0.80 & 11.2 & 0.29 & 19.3 & 0.55 & 0.29 & 0.29 & 16 & 0.07 & 2.1 & 0.21 & 17.5 & 0.59 & 24.2 & 0.4 \\
\hline $\mathrm{FI}$ & 0.2 & 0.95 & 2.1 & 0.98 & 19.4 & 0.54 & 0.54 & 0.54 & 41.9 & 0.55 & 5.9 & 0.9 & 2.3 & 0.93 & 6.6 & 0.88 \\
\hline FR & 0.32 & 0.56 & 7.3 & 0.79 & 15.4 & 0.8 & 0.79 & 0.56 & 18.8 & 0.09 & 5.6 & 0.88 & 17.2 & 0.6 & 40.8 & 0.11 \\
\hline $\mathrm{HU}$ & 0.38 & 0.11 & 13.6 & 0.06 & 20.1 & 0.49 & 0.06 & 0.06 & 71.8 & 0.96 & 1 & 0.05 & 23.7 & 0.41 & 16.8 & 0.62 \\
\hline IE & 0.43 & 0.01 & 12.5 & 0.13 & 14.4 & 0.84 & 0.13 & 0.01 & 8.9 & 0.03 & 0 & 0.01 & 40.8 & 0.11 & 15.0 & 0.68 \\
\hline IS & 0.15 & 0.98 & 6.3 & 0.86 & 18.7 & 0.6 & 0.6 & 0.60 & 15.5 & 0.07 & 7.8 & 0.97 & 7.1 & 0.87 & 9.2 & 0.83 \\
\hline LT & 0.49 & 0.00 & 2.4 & 0.98 & 12.6 & 0.9 & 0.9 & 0.00 & 62 & 0.9 & 4 & 0.68 & 12.3 & 0.76 & 13.3 & 0.73 \\
\hline LV & 0.28 & 0.76 & 4 & 0.95 & 13.8 & 0.87 & 0.87 & 0.76 & 53.3 & 0.79 & 1.1 & 0.05 & 23.4 & 0.42 & 27.2 & 0.33 \\
\hline $\mathrm{NL}$ & 0.34 & 0.40 & 11.1 & 0.3 & 17.6 & 0.67 & 0.3 & 0.30 & 16 & 0.07 & 0.4 & 0.02 & 21.2 & 0.47 & 11.0 & 0.79 \\
\hline $\mathrm{PL}$ & 0.42 & 0.02 & 13.8 & 0.05 & 6.4 & 0.98 & 0.05 & 0.02 & 41.6 & 0.54 & 2 & 0.18 & 20.6 & 0.49 & 22.5 & 0.44 \\
\hline SE & 0.14 & 0.99 & 4.2 & 0.95 & 15.9 & 0.77 & 0.77 & 0.77 & 34.7 & 0.36 & 10.9 & 1 & 1.5 & 0.94 & 6.1 & 0.89 \\
\hline SI & 0.26 & 0.83 & 8.6 & 0.67 & 2.5 & 0.99 & 0.67 & 0.67 & 48.4 & 0.7 & 2.6 & 0.35 & 23.0 & 0.43 & 26.5 & 0.34 \\
\hline SK & 0.44 & 0.01 & 14.7 & 0.03 & 21.5 & 0.29 & 0.03 & 0.01 & 53.7 & 0.8 & 0 & 0.01 & 19.1 & 0.53 & 26.1 & 0.35 \\
\hline UK & 0.42 & 0.02 & 11.2 & 0.29 & 19.1 & 0.57 & 0.29 & 0.02 & 12.1 & 0.05 & 0.4 & 0.02 & 43.3 & 0.09 & 13.9 & 0.71 \\
\hline
\end{tabular}




\section{Appendix 2: Raw and calibrated data and membership scores, discussion}

\begin{tabular}{|c|c|c|c|c|c|c|c|c|}
\hline \multirow[b]{2}{*}{ Country } & \multirow{2}{*}{$\begin{array}{l}\text { Leave should } \\
\text { be used } \\
\text { entirely by the } \\
\text { mother (\%) } \\
\text { Raw }\end{array}$} & \multirow{2}{*}{$\begin{array}{c}\text { Male recipients of } \\
\text { publicly } \\
\text { administered } \\
\text { parental leave (\%) } \\
\text { Raw }\end{array}$} & \multicolumn{6}{|c|}{ Universal caregiver configurations } \\
\hline & & & Calibrated & $\begin{array}{c}\lg L F^{*} C C^{*} \\
C A\end{array}$ & $\begin{array}{c}\lg { }^{*} L F^{*} C C^{*} C \\
a\end{array}$ & $\begin{array}{c}L G^{*} L F^{*} C C^{*} \\
C A\end{array}$ & $\begin{array}{c}L G^{*} L F^{*} C C^{*} \\
c a\end{array}$ & UCG \\
\hline AT & 0.35 & 4.3 & 0.62 & 0.25 & 0.2 & 0.75 & 0.2 & 0.75 \\
\hline $\mathrm{BE}$ & & 25.7 & 0.92 & 0.39 & 0.61 & 0.05 & 0.05 & 0.61 \\
\hline BG & 0.6 & & 0.01 & 0.07 & 0.07 & 0.12 & 0.12 & 0.12 \\
\hline $\mathrm{CZ}$ & 0.64 & 1.8 & 0.01 & 0.01 & 0.01 & 0.01 & 0.01 & 0.01 \\
\hline DE & 0.13 & 24.9 & 0.94 & 0.44 & 0.44 & 0.47 & 0.53 & 0.53 \\
\hline DK & 0.05 & 24.1 & 0.97 & 0.05 & 0.05 & 0.05 & 0.05 & 0.05 \\
\hline $\mathrm{EE}$ & & 6.5 & 0.18 & 0.01 & 0.01 & 0.18 & 0.18 & 0.18 \\
\hline ES & 0.3 & & 0.73 & 0.21 & 0.21 & 0.07 & 0.07 & 0.21 \\
\hline $\mathrm{FI}$ & 0.03 & 18.7 & 0.98 & 0.45 & 0.12 & 0.55 & 0.12 & 0.55 \\
\hline FR & 0.13 & 3.5 & 0.94 & 0.11 & 0.6 & 0.09 & 0.09 & 0.6 \\
\hline $\mathrm{HU}$ & & & & 0.04 & 0.04 & 0.05 & 0.05 & 0.05 \\
\hline IE & 0.15 & & 0.92 & 0.01 & 0.01 & 0.01 & 0.01 & 0.01 \\
\hline IS & 0.03 & 45.6 & 0.98 & 0.83 & 0.17 & 0.07 & 0.07 & 0.83 \\
\hline LT & 0.46 & & 0.14 & 0.1 & 0.1 & 0.68 & 0.27 & 0.68 \\
\hline LV & 0.56 & & 0.01 & 0.05 & 0.05 & 0.05 & 0.05 & 0.05 \\
\hline$N L$ & & & & 0.02 & 0.02 & 0.02 & 0.02 & 0.02 \\
\hline$P L$ & 0.3 & 1.6 & 0.73 & 0.18 & 0.18 & 0.18 & 0.18 & 0.18 \\
\hline SE & 0.01 & 45 & 0.98 & 0.64 & 0.11 & 0.36 & 0.11 & 0.64 \\
\hline SI & 0.38 & & 0.55 & 0.3 & 0.3 & 0.34 & 0.35 & 0.35 \\
\hline SK & 0.64 & & 0.01 & 0.01 & 0.01 & 0.01 & 0.01 & 0.01 \\
\hline UK & 0.16 & & 0.92 & 0.02 & 0.02 & 0.02 & 0.02 & 0.02 \\
\hline
\end{tabular}

Notes: ${ }^{*}$ The four configurations $\left(I g^{*} L F^{*} C C^{*} C A ; I{ }^{*} L F^{*} C C C^{*} C a ; L G^{*} L F^{*} C C{ }^{*} C A ; L G^{*} L F^{*} C C{ }^{*} C a\right)$ identify universal caregiver models (cf. table 2); UCG shows the maximum score among the four formulas. rule 


\begin{abstract}
'Conceptualizations and measurements of defamilialization have varied widely between studies, and recently several authors have underscored the need to reassess the extent to which defamilialization is still useful for the analysis of gender relations in the welfare state (Daly, 2011; Kurowska, 2016).
\end{abstract}

ii The inclusion of measures of quality of employment such as the gender wage gap is intended to emphasize the need to move beyond binary conceptualization of paid and unpaid work to incorporate other aspects of inequality within the two spheres. Further elements to be considered in future studies comprise the presence of gender specialization in the types of childcare tasks, workplace practices diminishing inequalities in working hours, wages, and horizontal and vertical segregation as well as the need to ensure that parents are warranted (well-paid) caregivers rights.

iii We used informtion from the following questions: Q16b: On average, how many hours a week do you spend looking after family members, e.g. children, elderly, ill or disabled family members? Q17b: And what about your spouse/partner? On average, how many hours a week does he/she spend looking after family members?

iv Given the focus of this paper on childcare policies, the use of disaggregated data on parental employment would have led to a more precise picture of employment outcomes, but this information was unfortunately not available for the set of countries analyzed. Nonetheless, previous research shows that parenthood plays an important role in explaining the overall gender wage and employment gap (Budig, M. \& Böckmann, 2010), and thus that the indicators chosen capture important aspects of the effects of childcare policy on wider gender equality outcomes in societies.

${ }^{\vee}$ EQLS 2012 contained also information on the quality of childcare service. However, this information is not included in our analysis given the issue of limited diversity which limits the number of conditions we could consider here but also because of the small percentage of individuals who reported this to be an issue across countries.

vi In case of Belgium and Estonia we used the actual share of male recipients because of missing data. Data for Hungary and the Netherlands was missing and these countries have been excluded from this analysis. 